\title{
Psychological Stress in the Era of Covid-19 Pandemic in Diabetic Population of Nagpur, India - A Cross Sectional Study
}

\author{
Jidnyasa Mankar1, Madhur Gupta², Arti Ajay Kasulkar³ \\ ${ }^{1,2}$ Department of Biochemistry, NKP SIMS \& RC and LMH, Nagpur, Maharashtra, India. ${ }^{3}$ Department of Forensic \\ Medicine \& Toxicology, NKP SIMS \& RC and LMH, Nagpur, Maharashtra, India
}

\section{ABSTRACT}

\section{BACKGROUND}

The global health care system has been impacted by the Covid-19 pandemic and lockdowns have been imposed to stop the virus from spreading. Due to rapid spread of corona virus, citizens are facing fear, anxiety, and depression directly affecting their mental health. Adults having poor health are at a higher risk of being infected. This situation has created a stressful atmosphere and resulted in the development of many psychological problems in individuals. Those having pre-existing conditions or co-morbidities have higher mortality risk as compared to healthy individuals. Hence, the issue is more common in people having co-morbidities, with diabetes mellitus being one common among them. We wanted to study the psychological impact mainly stress in diabetic population residing in rural setup in this era of Covid-19 outbreak.

\section{METHODS}

A cross-sectional study was conducted among 381 diagnosed diabetic patients attending outpatient department of Rural Health Training Centre affiliated to the tertiary care hospital. The collected data was entered and also analyzed for percentage, mean, standard deviation and variation coefficient.

\section{RESULTS}

Approximately half (51.96\%) of the participants reported a stress of moderate level during Covid-19 with mean \pm SD $(20.07 \pm 3.83)$, overall mean was $(21.55 \pm 8.67)$ and the variation coefficient was $40.22 \%$. The variance in stress level in diabetics with HbA1c levels of less than $6 \%, 6-8 \%$ and $>8 \%$ depicting the various levels of control of diabetes was $39.36,40.84$ and 40.50 respectively. Similarly the variance coefficient among stress was 42.39, 41.34, 34.65 and $32.12 \%$ when the duration of diabetes was compared in the respondents indicating that the stress level was widely distributed amongst all the participants.

\section{CONCLUSIONS}

Strategies need to be implemented to take care of mental health in diabetic patients especially in this Covid pandemic era.

\section{KEY WORDS}

Stress, COVID-19 Pandemic, Diabetes Mellitus, Rural Population
Corresponding Author: Dr. Arti Ajay Kasulkar, Associate Professor,

Dept. of Forensic Medicine \& Toxicology, NKP Salve Institute of Medical Sciences \& Research Center and Lata Mangeshkar Hospital, Digdoh Hills, Hingana Road- 440019, Nagpur, Maharashtra, India. E-mail: artinarde@rediffmail.com

DOI: $10.14260 / \mathrm{jemds} / 2021 / 503$

How to Cite This Article:

Mankar J, Gupta M, Kasulkar AA. Psychological stress in the era of Covid-19 pandemic in diabetic population of Nagpur, India - a cross sectional study, India. J Evolution Med Dent Sci 2021;10(31):2460-2464, DOI: $10.14260 / j e m d s / 2021 / 503$

Submission 30-04-2021,

Peer Review 03-07-2021,

Acceptance 10-07-2021,

Published 02-08-2021.

Copyright (c) 2021 Jidnyasa Mankar et al. This is an open access article distributed under Creative Commons Attribution License [Attribution 4.0 International (CC BY 4.0)] 


\section{BACKGROUND}

Concerns about the Covid-19 pandemic's effect on psychological health and well-being are widespread. Corona virus disease 2019 (Covid-19) is a viral infectious disease caused by the corona virus which is now called severe acute respiratory syndrome corona virus 2 (SARS-CoV-2). Due to rapid spread of corona virus, citizens are facing fear, anxiety, and depression directly affecting the mental health. Older adults with poor health are at a high risk of getting infections. This situation has created a stressful atmosphere and resulted in the development of many psychological problems in individuals. Those who do not have pre-existing conditions or co-morbidities have mortality risk of about $1 \%$. The issue is more common in people having co-morbidities with diabetes mellitus being one among them. Diabetes mellitus (DM) is a long-term metabolic disorder characterized by hyperglycemia resulting from defects in insulin secretion, insulin action, or both micro and macrovascular complications. Diabetes mellitus is found all over the world, but it is more prevalent (particularly type 2 ) in developing and developed countries. In India, diabetes has now been diagnosed in over 30 million people. The CPR (Crude Prevalence Rate) in India's urban areas is estimated to be 9 $\%$. The incidence is approximately $3 \%$ of the total population in rural areas. India's population has surpassed 1000 million , which gives us a sense of the scale of the issue. Acute and chronic inflammation are linked to Covid-19 and diabetes, respectively. In terms of clinical development and outcome, both diseases can have an effect on each other. Though the literature review focuses mainly on clinical treatment, diabetic patients are likely to be impacted by Covid-19 both within and outside of the health-care setting, with particular concerns about diet and physical activity disturbances, increased stress on mental health and wellbeing. Diabetes affected 422 million adults worldwide in 2014, and this number is projected to rise to 552 million by $2030,{ }^{1}$ with the burden falling disproportionately on low and middle income countries. In the age group of $20-79$ years among them, India alone has 65.1 million individuals with diabetes. ${ }^{2}$ These figures in millions and doubling rate is quite alarming, and the so called status symbol tags are now becoming stress symbols tags with an impregnation in the rural area.

With our country approaching the population numbers predicted to be attained by 2030 , in 2020 itself it is ready to explode like a bomb. It may be more difficult to treat a viral infection in people with diabetes. There tends to be two explanations for this. First, the immune system is weakened, making it more difficult to combat the infection and resulting in a longer recovery time. Second, the virus can thrive in a high-blood-glucose environment. Thus the Covid-19 infection is a double challenge for diabetics. ${ }^{3}$ The reason for poor prognosis in people with diabetes is likely to be multifactorial and may include age, sex, ethnicity, co-morbidities such as hypertension and cardiovascular disease, obesity etc all contributing to the risk of worse outcomes. In India, the healthcare facilities in the rural areas are less as compared to metropolitan cities. Because of this COVID pandemic, people are finding it more difficult to reach out to the nearest healthcare facility to even check their blood sugar and getting medicines for diabetes. Due to lockdown measures which have been instituted by the authorities, people are dealing with financial crises, health problems and significant psychological strain influencing their lives subsequently having a great impact on their psychological well being. It is said that diabetes and psychiatric disorders share a bidirectional relationship and both influence each other in multiple ways. ${ }^{4}$ Diabetes anxiety, psychological insulin tolerance, and the irrational fear of hypoglycemic episodes are all symptoms that can be exacerbated by coexisting diabetes and coping with the disorder becomes difficult. ${ }^{5}$ Thus when the focus has mostly been on testing, there is a need to find a cure and mechanism which will prevent psychological problems in coping with the current fear of the disease.

The psychological effects of natural disasters or epidemics on people with diabetes, especially in rural areas, are poorly documented. Keeping this in mind, it was thought to study the psychological impact mainly stress in diabetic population residing in rural setup in this Covid-19 outbreak era which is considered to be an uncontainable traumatic life event.

\section{METHODS}

A cross-sectional analytical study was conducted from June 2020 to July 2020 among diagnosed cases of diabetes mellitus attending outpatient department of Rural Health Training Centre affiliated to the tertiary care hospital during Covid-19 pandemic lockdowns. Universal sampling method was used to recruit the study participants. As per Census India 2011, with a total population of Katol being 43267, the margin of error of $\pm 5 \%$, and a confidence level of $99 \%$ with $50 \%$ response distribution, a minimum sample of 381 was calculated by online software RAOSOFT. ${ }^{6}$

After IEC approval, informed consent was taken and maintaining confidentiality and anonymity of the participants', data collection was done by interview following social distancing protocols for Covid-19. The duration of diabetes mellitus was noted and plasma HbA1c of the participants was done by High Performance Liquid chromatography to assess the control of the disease. The predesigned and pre-tested ten-item questionnaire by Cohen ${ }^{7}$ was used to measure the perception of stress (Perceived Stress Scale-10) in Hindi / Marathi version which was translated and validated by the members of Medical Education Unit. The questionnaire contained items depicting the feelings and thoughts of the participants during the last one month. Each item in 5-point Likert scale was scored from 0 (never) to 4 (very often) with a total score ranging from 0 to 40 . The higher scores displayed higher perceived Covid-19 stress in the participants. Scores which ranged from 0 to 13 reflected a low perceived stress in the respondents whereas scores ranging from 14 to 26 were considered moderate perceived stress in the studied population. Intermediate scores which ranged from 27 to 40 were considered as high perceived stress.

\section{Ethical Statement}

IEC was approved in the Department of Rural Health Training Centre affiliated to the tertiary care hospital during Covid-19 
pandemic lockdowns, from NKP Salve Institute of Medical Sciences \& Research Center and Lata Mangeshkar Hospital.

\section{Statistical Analysis}

With the help of Microsoft Excel and Statistical Package for Social Sciences (SPSS) version 25, the collected data was entered and also analyzed for percentage, mean, standard deviation and variation coefficient (The higher the coefficient of variation, the greater the level of dispersion around the mean).

\section{RESULTS}

The current study was carried out among 381 diabetics. Of these, 180 were females and 201 were males. The duration of the diabetes was less than 5 years in 73 participants and 84 had diabetes for more than 5 years.

The stress level was observed among participants using pre-designed, validated, translated, pilot tested and pretested perceived stress scale (PSS-10) in the participants in relation to duration of diabetes and HbA1c levels (Table 1 and Table 2).

\begin{tabular}{|cccc|}
\hline $\begin{array}{c}\text { Duration of Diabetes } \\
\text { Mellitus in Years }\end{array}$ & $\begin{array}{c}\text { Number of } \\
\text { Participants }\end{array}$ & $\begin{array}{c}\text { Perceived Stress } \\
\text { Level }\end{array}$ & $\begin{array}{c}\text { Variation } \\
\text { Coefficient }\end{array}$ \\
< 5 years & $73(19.16 \%)$ & $23.26 \pm 9.8$ & 42.39 \\
$5-10$ years & $217(56.95 \%)$ & $20.65 \pm 8.54$ & 41.34 \\
$10-15$ years & $71(18.63 \%)$ & $21.49 \pm 7.44$ & 34.65 \\
$>15$ years & $20(5.24 \%)$ & $25.35 \pm 8.14$ & 32.13 \\
\hline \multicolumn{4}{|c|}{ Table 1: Stress Levels among Participants during } \\
Covid-19 Lockdowns in Relation to Duration of Diabetes (in Years) \\
\hline
\end{tabular}

\begin{tabular}{|cccc|}
\hline HbA1c $\%$ & $\begin{array}{c}\text { Number of } \\
\text { Participants }\end{array}$ & $\begin{array}{c}\text { Perceived Stress } \\
\text { Level }\end{array}$ & $\begin{array}{c}\text { Variation } \\
\text { Coefficient }\end{array}$ \\
$<6$ & $102(26.84 \%)$ & $21.57 \pm 6.49$ & 39.36 \\
$6.1-8$ & $157(41.20 \%)$ & $21.33 \pm 8.64$ & 40.84 \\
$>8$ & $122(32.02 \%)$ & $21.83 \pm 8.91$ & 40.50 \\
\hline \multicolumn{4}{|c|}{ Table 2. Stress Levels among Participants during } \\
Covid-19 Lockdown in Relation to HbA1c Level
\end{tabular}

We noted that approximately half (51.96\%) of the study population had a moderate level of stress as per the scale used during this pandemic of Covid-19 with a mean value (20.07 \pm 3.83 ). During Covid-19, $17.5 \%$ of the rural diabetes patients showed a low level of stress on the perceived scale, with a mean value $(8.76 \pm 2.69)$. The findings indicated that a high level of stress by the participants was reported by 30.48 $\%$ of them with mean \pm SD $(31.38 \pm 4.53)$ during Covid- 19 . The data also revealed that the average mean of stress during Covid-19 for the study participants was $(21.55 \pm 8.67)$, with a variance coefficient of $40.22 \%$ among stress levels during Covid-19. The perceived stress level in patients with HbA1c level between $6.1-8 \%$ was $41.2 \%$ as compared to those with a level of $>8 \%$ (indicating poor compliance of control) which was $32 \%$. The variance in stress level in diabetics with HbA1c levels of less than $6 \%, 6$ - $8 \%$ and > $8 \%$ depicting the various levels of control of diabetes was 39.36, 40.84 and 40.50 respectively. Similarly the variance coefficient among stress was $42.39,41.34,34.65$ and $32.12 \%$ when the duration of diabetes was compared in the respondents indicating that the stress level was widely distributed amongst all the participants.

\section{DISCUSSION}

Qualitative inquisition is often used to collect data regarding lay attitudes and social interactions, which can be used to investigate the micro-level health effects of macro-level politics and economics, as well as cultural values, which may play a role in disease management. In this study, we tried to evaluate the psychological stress in people living with diabetes after 1 month of social distancing recommendations in a rural set up in India. India's financially viable growth has coincided with a sharp increase in diabetes cases. The gap between urban and rural diabetes is closing due to the globalisation of unhealthy lifestyles. India, the world's second most populous nation, is now afflicted by the COVID pandemic, which has been exacerbated by the global diabetes epidemic. The disease profile of Covid-19 is dynamic and continues to rapidly evolve causing distressing behaviour in individuals. Corona virus disease 2019 (Covid-19) is a pandemic viral outbreak that has recently devastated the world, with the resulting morbidity and mortality being significantly higher in those with non-communicable disease. Diabetics are clinically vulnerable in the COVID phase, meaning they are at a higher risk of serious illness from the corona virus. In India, especially in rural areas, diabetes knowledge and awareness are lacking. The Covid-19 pandemic has caused an understandable fear and anxiety among diabetes. People have been restricted to their homes, unable to visit families, working differently or not at all, certain supplies have been interrupted, and health care plans have changed or paused in general.

Diabetes mellitus and psychiatric disorders contribute to a reciprocal relationship and the confrontation of living and prevailing over the diabetes may result in poignant overwork, and the presence of depression and anxiety symptoms in such patients may be linked with lower treatment observance, and often leading to worsening of control of the disease. It is already known that diabetes as a disease is frequently linked with a considerable psychological and emotional overload with a burden of the self-care course of therapy and tension in social relationships. The result of this is that many people experience varying distress, abnormal mood swings with an altered level of anxiety. Stress and diabetes are two way processes and interrelated. People with diabetes are already at risk of psychiatric disorders, and people with serious mental illness are more likely than the general population to have diabetes. The relationship between the non communicable diseases which is diabetes and also mental health disorders could be intensified in a atmosphere which is stressful. This varied psychological distress could alter the associated depressive symptoms and may cause unwarranted outcomes related to the disease. It is well known that pandemics pose a threat to mental health. ${ }^{8}$ The surfacing of this fatal pandemic has poised a new rationale for insecurity and apprehension in this group of patients.

Prevention of the spread of Covid-19 has initiated a lot many measures which have been incorporated to prevent the spread and they involve the seclusion of cases which are suspects, keeping a track and monitoring of the near contacts, and relaying of the information at both the regional and national level with the proposition of maintaining social 
distance, especially for high risk groups such as patients with diabetes. A study by Alssi J et al. ${ }^{9}$ revealed that $53.8 \%$ of individuals experienced psychological anguish during the early stage of the Covid-19 outbreak and the array of pessimistic psychological responses were identified as worries about individuals' own health and family, anxiety, depression and insomnia.

It is well documented from the previous studies that depression and anxiety are more widespread among patients with diabetes than the general population. ${ }^{10}$ Our study revealed that approximately half of the respondents had a moderate level of stress during Covid-19 era.11,12 The psychological outcome of the existing circumstances in patients with diabetes is still theoretical. Such individuals due to the conditions of the underlying disease and other comorbidities already have enormous tendency to develop psychiatric disorders throughout their lives. It is likely that due to the Covid-19 pandemic, the social segregation and isolation in this period, may impede with certain parameters of mental health in patients with diabetes. The effect of Covid19 made us think about the possible impact of the stressor associated on diabetics more so in rural population. Living with diabetes can be stressful and anxiety-inducing, with the relentless pressures wreaking havoc on one's mental health. Because of the high incidence of diabetes, depression and psychological co-morbidity, as well as the detrimental effects on glycemic regulation, early morbidity, and quality of life, it is recommended that people with diabetes be screened on a regular basis using validated questionnaires or clinical interviews. ${ }^{13}$ One of the most important aspects of ensuring improved diabetes care and management is education. There are also evidences that indicate the growing awareness of diabetes and its complications that have important benefits, such as improvement in treatment compliance and therefore a reduction in diabetes complications. This may hold true for the psychological agony that the diabetic patients undergo.

Despite the fact that India was one of the first developed countries to establish a National Mental Health Program, the programme is underfunded and faces difficulties in implementing mental health services and promotion activities. The general perception in India that depression is a social issue can explain the low investment in mental health care. ${ }^{14}$ Evaluation of mental health services for people with diabetes can help them boost not only their diabetes self-care and reduce complications, but it can also help them regain overall acquiescence to their diabetes treatment. While mental health can be a major barrier to diabetes care in the current environment, the emphasis must turn to incorporation of mental health into diabetes care, especially in terms of the consequences of untreated depression among people with diabetes.

\section{CONCLUSIONS}

In our study, even though we were not having an investigative purpose, the study found a high number of diabetic patients presenting evidence of noteworthy psychological stress during the Covid-19 pandemic. This study thus highlights the need for mental health admittance and sustenance for patients with diabetes. This can serve as a food for thought about the impact that the present scenario may have on the mental health of patients with diabetes and strategies which need to be implemented to care of mental health in diabetes.

\section{Limitations}

Some limitations of the present study include that the status of stress in the diabetic population was not assessed prior to the COVID times in the same population. Being a cross sectional study, there was no control group taken into consideration. Moreover, though the data was taken as per sample size calculation, the study could not be extrapolated to the whole population. Lastly the respondents were selected from a single rural setup and hence the external validity of the study was limited. Thus, our findings indicate that diabetes management in Covid-19 patients is a significant clinical challenge that necessitates an integrated team approach, in which mental wellbeing can be an important strategy for reducing stress in these patients.

Data sharing statement provided by the authors is available with the full text of this article at jemds.com.

Financial or other competing interests: None.

Disclosure forms provided by the authors are available with the full text of this article at jemds.com.

\section{REFERENCES}

[1] WHO. Global report on diabetes. World Health Organization 2016. Accessed on March 31, 2020. https://apps.who.int/iris/bitstream/handle/10665/204 871/9789241565257_eng.pdf;jsessionid=0DD089D400 AA949335F93FCC94F55256?sequence $=1$

[2] IDF Diabetes Atlas. $6^{\text {th }}$ edn. International Diabetes Federation 2013: p. 157.

[3] Madsbad S. COVID-19 Infection in people with diabetes. Touch Endocrinology 2020. https://www.touchendocrinology.com/insight/Covid19-infection-inpeople-with-diabetes

[4] Balhara YPS. Diabetes and psychiatric disorders. Indian J Endocr Metab 2011;15(4):274-83.

[5] Hasan SS, Clavarino AM, Mamun AA, et al. Anxiety symptoms and the risk of diabetes mellitus in Australian women: evidence from 21-year follow-up. Public Health 2016;130:21-8.

[6] Raosoft. Sample Size Calculator 2020. http://www.raosoft.com/samplesize.html (accessed Nov $16,2020)$

[7] Cohen S, Kamarck T, Mermelstein R. A global measure of perceived stress. J Health Soc Behav 1983;24(4):385-96.

[8] Rajkumar RP. COVID-19 and mental health: a review of the existing literature. Asian J Psychiatr 2020;52:102066.

[9] Alessi J, De Oliveira GB, Franco DW, et al. Mental health in the era of COVID-19: prevalence of psychiatric disorders in a cohort of patients with type 1 and type 2 diabetes during the social distancing. Diabetol Metab Syndr 2020;12:76.

[10] Ali S, Stone MA, Peters JL, et al. The prevalence of comorbid depression in adults with Type 2 diabetes: a 
systematic review and meta-analysis. Diabet Med 2006;23(11):1165-73.

[11] Smith KJ, Béland M, Clyde M, et al. Association of diabetes with anxiety: a systematic review and metaanalysis. J Psychosom Res 2013;74(2):89-99.

[12] Anderson RJ, Freedland KE, Clouse RE, et al. The prevalence of co-morbid depression in adults with diabetes: a meta-analysis. Diabetes Care 2001;24(6):1069-78.

[13] Robinson DJ, Coons M, Haensel H, et al. Diabetes and mental health. Can J Diabetes 2018;42(Suppl 1):130-41.

[14] Patel V, Price M. Ageing and mental health in a developing country: who cares? Qualitative studies from Goa, India. Psychol Med 2001;31(1):29-38. 